\title{
Effect of a Phosphodiesterase 5 Inhibitor on Pulmonary and Cerebral Arteries of Newborn Piglets with Chronic Hypoxia-Induced Pulmonary Hypertension
}

\author{
Candice D. Fike $^{\mathrm{a}}$ Mark Kaplowitz $^{\mathrm{a}}$ Yongmei Zhang ${ }^{\mathrm{a}}$ Mark Dantuma $^{\mathrm{b}}$ \\ Jane A. Madden ${ }^{\text {b }}$ \\ a Department of Pediatrics, Vanderbilt University School of Medicine and the Monroe Carell Jr. Children's Hospital \\ at Vanderbilt, Nashville, Tenn., and ${ }^{b}$ Research Services Zablocki VAMC and Department of Neurology, \\ Medical College of Wisconsin, Milwaukee, Wisc., USA
}

\section{Key Words}

Cerebral autoregulation - Phosphodiesterase 5 expression •

Zaprinast $\cdot$ Middle cerebral arteries

\begin{abstract}
Background: The use of phosphodiesterase 5 (PDE5) inhibitors to treat newborns with pulmonary hypertension is increasing. The effect of PDE5 inhibitors on the neonatal cerebral circulation remains unknown. The neonatal piglet model of chronic hypoxia-induced pulmonary hypertension allows the study of the effects of PDE5 inhibitors on both the pulmonary and cerebral circulations. Objectives: To determine whether the PDE5 inhibitor, zaprinast, causes dilation in pulmonary and middle cerebral arteries (MCA) of normoxic newborn piglets and those with chronic hypoxia-induced pulmonary hypertension, and to evaluate whether zaprinast alters responses to increased pressure (autoregulatory ability) of the MCA. Methods: Two-day-old piglets were raised in normoxia or hypoxia for 3 or 10 days. Pulmonary arteries and MCA were isolated and pressurized, after which changes in diameter to zaprinast were measured. MCA pressure-diameter relationships were determined. Results: Dilation to zaprinast was similar in pulmonary arteries from normoxic and hypoxic piglets. Zaprinast dilated MCA from all groups but the response was diminished in MCA from piglets raised
\end{abstract}

in hypoxia for 10 days. MCA pressure-diameter relationships (autoregulation) did not differ between the groups. Conclusions: Pulmonary artery dilation to zaprinast supports the use of PDE5 inhibitors to treat pulmonary hypertension in neonates. PDE5 inhibitors function as MCA dilators but do not impair the pressure-diameter behavior of the cerebral circulation of either normoxic newborn piglets or those with chronic hypoxia-induced pulmonary hypertension. These findings suggest that cerebral autoregulation is likely to be intact with acute PDE5 inhibitor treatment in infants with pulmonary hypertension in conditions associated with chronic hypoxia.

Copyright $\odot 2011$ S. Karger AG, Basel

\section{Introduction}

There is an increasing number of reports of the use of phosphodiesterase 5 (PDE5) inhibitors to treat pulmonary hypertension in infants [1-15]. In particular, there is a growing interest to use the PDE5 inhibitor, sildenafil, to treat newborns with pulmonary hypertension in situations where limited resources exclude the use of expensive inhaled nitric oxide (NO) therapy $[2,6,10]$. Furthermore, sildenafil both enhances the efficacy of and facilitates the weaning process from inhaled NO $[1,9,15]$. The

\section{KARGER}

두 2011 S. Karger AG, Basel

Fax +41613061234 E-Mail karger@karger.ch www.karger.com
Accessible online at: www.karger.com/neo
Candice D. Fike, MD

Department of Pediatrics, Vanderbilt University School of Medicine and the Monroe Carell Jr. Children's Hospital at Vanderbilt

2215 B Garland Ave., 1125 MRB IV/Light Hall, Nashville, TN 37232-0656 (USA)

Tel. +1 615936 8403, E-Mail Candice.fike@vanderbilt.edu 
duration of sildenafil therapy in infants and children ranges from a few hours and days for treatment of acute pulmonary hypertension $[2,6,10,12]$ to prolonged therapy over weeks and even months for treatment of chronic forms of pulmonary hypertension $[3,7,14]$.

The growing clinical use of PDE5 inhibitors for treatment of both acute and chronic neonatal pulmonary hypertension is based in large part on the knowledge that PDE5 is a cGMP-degrading phosphodiesterase that is abundantly expressed in lung tissue [16]. However, PDE5 is expressed in various other tissues, including the brain [17]. Thus, the effects of PDE5 inhibitors may not be limited to the pulmonary vasculature, yet, their effects on other vascular beds such as the neonatal cerebral circulation, are either very limited or not known $[18,19]$.

The neonatal cerebral circulation is known for its limited autoregulatory ability, that is, the cerebral arteries are able to maintain a constant diameter in response to increasing pressure over a very narrow range compared to adult arteries [20]. Any modification of this already limited ability by a PDE5 inhibitor could potentially have serious consequences for the neonatal cerebral circulation. Moreover, the possibility that a PDE5 inhibitor causes cerebral dilation which could alter brain blood flow remains to be explored. Since an increasing number of infants with pulmonary hypertension are being treated with PDE5 inhibitors it is vital that more information about the effects of these drugs on the cerebrovasculature of the newborn be made available.

Our laboratory has previously shown that exposing neonatal piglets to chronic hypoxia from day of life 2 until either day of life 5 or 10, that is, for either 3 or 10 days of hypoxia, produces pulmonary hypertension [21, 22]. This model was therefore used to accomplish the major purposes of this study, to determine whether the PDE5 inhibitor, zaprinast, functions as a vasodilator in pulmonary and cerebral arteries from these animals, and whether it alters the autoregulatory ability of the middle cerebral arteries (MCA). We used zaprinast for these studies as there is no commercially available preparation of sildenafil that can be solubilized to make the accurate concentrations needed for in vitro studies.

\section{Methods}

Animals

For the hypoxic animals, piglets were placed in a hypoxic normobaric environment on day of life 2 and kept in this hypoxic environment until either day of life 5 ( 3 days of hypoxia) or day of life 12 (10 days of hypoxia). While in the hypoxic environment, oxygen content was regulated at $10-12 \% \mathrm{O}_{2}\left(\mathrm{PO}_{2}\right.$ 64-78 Torr). $\mathrm{CO}_{2}$ was absorbed with soda lime and $\mathrm{PCO}_{2}$ was maintained at 3-6 Torr. The chamber was opened twice daily for cleaning and to weigh the animals. The piglets were fed ad libitum with artificial sow milk. For the normoxic groups of animals, piglets were used on the day of arrival from the vendor at postnatal ages of either 5-6 days or 12 days, which compared to the postnatal ages of the hypoxic piglets when they were studied. We have previously found no differences in vascular responses between piglets raised by us in a room air, normoxic, environment from day of life 2 to either day of life 5 or 12 and piglets raised by the vendor [21, 22]. Henceforth in the manuscript, ' 3 day exposure group' will be used to refer to piglets raised by the vendor in normoxia from birth to day of life 5-6 or by us in hypoxia from day of life 2 until day of life 5 ( 3 days exposure to hypoxia), while ' 10 day exposure group' will be used to refer to piglets raised by the vendor in normoxia from birth to day of life 12 or by us in hypoxia from day of life 2 until day of life 12 (10 days exposure to hypoxia).

All piglets were preanesthetized with ketamine $(30 \mathrm{mg} / \mathrm{kg}$ i.m.) and acepromazine ( $2 \mathrm{mg} / \mathrm{kg}$ i.m.), anesthetized with pentobarbital (10 mg/kg i.v.), heparinized (1,000 IU/kg heparin i.v.), and then exsanguinated. The thorax was opened, the lungs were removed and placed in cold $\left(4^{\circ} \mathrm{C}\right)$ physiologic saline solution (PSS) until use. Next, the skull was opened, the brain was removed, and the MCA were isolated, placed in cold PSS and kept on ice while transported overnight to Dr. Madden's lab.

All experimental protocols adhered to the National Institutes of Health guidelines for the use of experimental animals and were approved by the Animal Care and Use Committee of Vanderbilt University Medical Center. This animal resource facility is fully accredited by the Association for Assessment and Accreditation of Laboratory Animal Use.

Cannulated Pulmonary Artery and MCA Preparations

Using our previously published methods, piglet resistance level pulmonary arteries (PRAs, 80-200 $\mu \mathrm{m}$ diameter) [23] and MCA [24] were isolated, cannulated and pressurized for continuous measurement of diameter. Briefly, an arterial segment was threaded onto a proximal cannula and tied in place. The distal end of the artery was then tied onto the distal cannula and the artery was filled with PSS. The distance between the cannula tips was adjusted with a micrometer connected to the proximal cannula so that the slack was taken out of the artery. The exterior of the artery was suffused with PSS from a reservoir at $37^{\circ} \mathrm{C}$ and aerated with a gas mixture containing $\mathrm{O}_{2}, \mathrm{CO}_{2}$ and $\mathrm{N}_{2}$, giving a $\mathrm{PO}_{2}$ of 140 Torr, a $\mathrm{PCO}_{2}$ of 38 Torr and a $\mathrm{pH}$ of 7.37. The arterial lumen was gravity filled from a syringe containing Krebs and connected to the cannula with polyethylene tubing.

Inflow pressure was adjusted by changing the height of the infusion syringe. Pressure transducers were placed at the inflow side between the syringe and the artery and at the outflow end of the system. The artery was discarded if the pressures were not equal (indicating a leak in vessel). The arteries were observed continuously with a video system containing a color camera (Hitachi VCC-151) and television monitor. Vessel diameters were measured with a video scaler (model IV 550; FOR A). The video scaler was calibrated with a micrometer scale. 


\section{Cannulated PRA Protocols}

Each PRA was allowed to equilibrate for $30 \mathrm{~min}$ to establish basal tone. Normoxic and hypoxic PRAs were equilibrated at transmural pressures that represented in vivo pressures [21, 22]: $15 \mathrm{~cm} \mathrm{H}_{2} \mathrm{O}$ for normoxic arteries and $25 \mathrm{~cm} \mathrm{H}_{2} \mathrm{O}$ for the hypoxic arteries. We have previously shown no effect from these transmural pressures on pulmonary arterial responses to acetylcholine (ACh) [23]. Following establishment of basal tone, all PRAs were tested for viability by contraction to the thromboxane mimetic, $\mathrm{U} 46619\left(10^{-8} \mathrm{M}\right)$. Dilation to $\mathrm{ACh},\left(10^{-6} \mathrm{M}\right)$ indicated a functional endothelium in normoxic PRAs. Dilation to A23187, another endothelium-dependent agent, was used to verify a functional endothelium in PRAs from hypoxic piglets since we had previously found that vessels from these animals constricted to ACh but would dilate to the calcium ionophore, A23187 [23]

Zaprinast was added cumulatively $\left(10^{-8}\right.$ to $\left.5 \times 10^{-5} \mathrm{M}\right)$ to PRA from normoxic and hypoxic piglets equilibrated at basal tone and the change in vessel diameter measured. In another set of studies, the influence of elevated tone on the PRA response to zaprinast was assessed. Tests for viability and a functional endothelium were performed as described above, and then either endothelin or the thromboxane mimetic U44619 was added until the PRA diameter had decreased by $30-40 \%$. After equilibration at the elevated tone, dose responses to zaprinast were performed.

\section{Cannulated MCA Protocols}

Each MCA was allowed to equilibrate for $60 \mathrm{~min}$ to establish basal tone. We have previously shown that systemic aortic pressure does not differ between normoxic piglets and piglets with chronic hypoxia-induced pulmonary hypertension [21, 22]. Therefore, both normoxic and hypoxic MCAs were equilibrated at a transmural pressure of $60 \mathrm{~mm} \mathrm{Hg}$. All MCAs were tested for viability by contraction to $\mathrm{KCl}(80 \mathrm{mM})$ and checked for the presence of a functional endothelium by evaluating the dilation to ACh $\left(10^{-6} \mathrm{M}\right)$.

In one series of studies, changes in vessel diameter in response to zaprinast $\left(10^{-8}\right.$ to $\left.5 \times 10^{-5} \mathrm{M}\right)$ were measured in MCAs from normoxic and hypoxic piglets. In another series of studies, to determine whether differences in responses to zaprinast involve alterations in NO signaling downstream from NO production, changes in vessel diameter in response to the NO donor, S-nitroso-N-acetyl-penicillamine (SNAP, $10^{-8}$ to $10^{-4} \mathrm{M}$ ) were measured. Because MCAs spontaneously develop and maintain tone, it was not necessary to constrict the vessels with a vasoactive agent prior to assessing the effect of zaprinast or SNAP.

Another series of studies evaluated the effect of zaprinast on the pressure-diameter behavior (autoregulatory ability) of MCAs from all groups of piglets. Tests for viability and a functional endothelium were performed as described above. The transmural pressure was then increased from 20 to $120 \mathrm{~mm} \mathrm{Hg}$ in $10-\mathrm{mm} \mathrm{Hg}$ increments and vessel diameter measured at each pressure step after the response had stabilized (within $2 \mathrm{~min}$ ). In some studies, zaprinast $\left(10^{-5} \mathrm{M}\right)$ was added to the reservoir and allowed to circulate for $15 \mathrm{~min}$ prior to measuring the pressure-diameter behavior of MCAs from each group of piglets. For both PRA and MCA cannulated artery studies, vessel responses to the vehicle used for solubilization of the zaprinast or SNAP were also evaluated.
Immunoblot Analysis of PDE5, NOS 1 and NOS 3

These studies were performed to determine whether differences in responses to zaprinast involve altered expression of PDE5, NOS 1 or NOS 3. Pulmonary arteries ( $\leq 300 \mu$ m diameter) and MCAs dissected from lungs and brains of normoxic and hypoxic piglets of all groups were frozen in liquid nitrogen and stored at $-80^{\circ} \mathrm{C}$ until use for immunoblot analysis. Note that we previously found no difference in either NOS 1 or NOS 3 expression between PRAs from piglets raised in hypoxia and comparable age normoxic piglets $[25,26]$. Therefore, studies evaluating NOS expression were only performed with MCAs. We have been unable to detect NOS 2 expression in piglet tissue by immunoblot with commercially available antibodies.

Preliminary studies were done with different amounts of total protein in order to determine the dynamic range of the immunoblot analysis. An amount of protein that was within the dynamic range of the immunoblot analysis was then used to compare protein abundances between homogenates of small pulmonary arteries and MCAs from normoxic and hypoxic piglets of the 3 and 10 day exposure groups as described below.

Frozen samples of small pulmonary arteries and MCAs from all groups of piglets ( $n=5$ for each group) were crushed under liquid $\mathrm{N}_{2}$ in a prechilled mortar and pestle into a fine powder, transferred to a tube containing homogenization buffer with protease inhibitors, then sonicated using three 15-second pulses, taking care not to foam the sample. Protein concentrations for all homogenates were determined by protein assay (Bradford). All homogenates were diluted with phosphate-buffered saline (PBS) to obtain a protein concentration of $1 \mathrm{mg} / \mathrm{ml}$. Aliquots of the protein solutions were solubilized in an equal volume of denaturing, reducing sample buffer, heated to $80^{\circ} \mathrm{C}$ for $15 \mathrm{~min}$, and centrifuged for $3 \mathrm{~min}$ at 5,600 $\mathrm{g}$ in a microfuge. Equal volumes of these supernatants were applied to Tris-glycine precast $4-20 \%$ polyacrylamide gels (Novex Co.) so that equal amounts of protein were loaded. Electrophoresis was carried out in $25 \mathrm{mM}$ Tris, $192 \mathrm{mM}$ glycine and 0.1\% SDS ( $\mathrm{pH} 8.3$ ) at $125 \mathrm{~V}$ for $1.7 \mathrm{~h}$. The proteins were transferred from the gel to a nitrocellulose membrane (Novex Co.) using a Bio-Rad transfer box at $100 \mathrm{~V}$ for $1 \mathrm{~h}$ in $25 \mathrm{~mm}$ Tris, $192 \mathrm{~mm}$ glycine and $20 \%$ methanol $(\mathrm{pH}=8.3)$. The membrane was incubated overnight at $4^{\circ} \mathrm{C}$ in PBS containing $10 \%$ nonfat dried milk and $0.1 \%$ Tween- 20 to block nonspecific protein binding. To detect the protein of interest, the nitrocellulose membrane was incubated overnight at $4{ }^{\circ} \mathrm{C}$ with the primary antibody $(1: 1,000$ PDE5 from Calbiochem; 1:1,000 NOS 1 and 1:1,000 NOS 3 from Transduction Laboratories) diluted in PBS containing $0.1 \%$ Tween- 20 and $1 \%$ nonfat dried milk (carrier buffer), followed by incubation for $1 \mathrm{~h}$ at room temperature with a horseradish peroxidase-conjugated secondary antibody (Zymed) diluted in the carrier buffer $(1: 5,000)$. The nitrocellulose membrane was washed 3 times between the first two incubations with the carrier buffer and 3 times with the carrier buffer plus 1 time with PBS containing $0.1 \%$ Tween-20 following the final incubation. To visualize the antibody, the membranes were developed using enhanced chemiluminescence reagents (ECL; Amersham Co.) and the chemiluminescent signal was captured on X-ray film (ECL Hyperfilm; Kodak). Similar procedures were followed to reprobe the membranes for $\beta$-actin (Sigma). The bands for each protein were quantified using densitometry. 

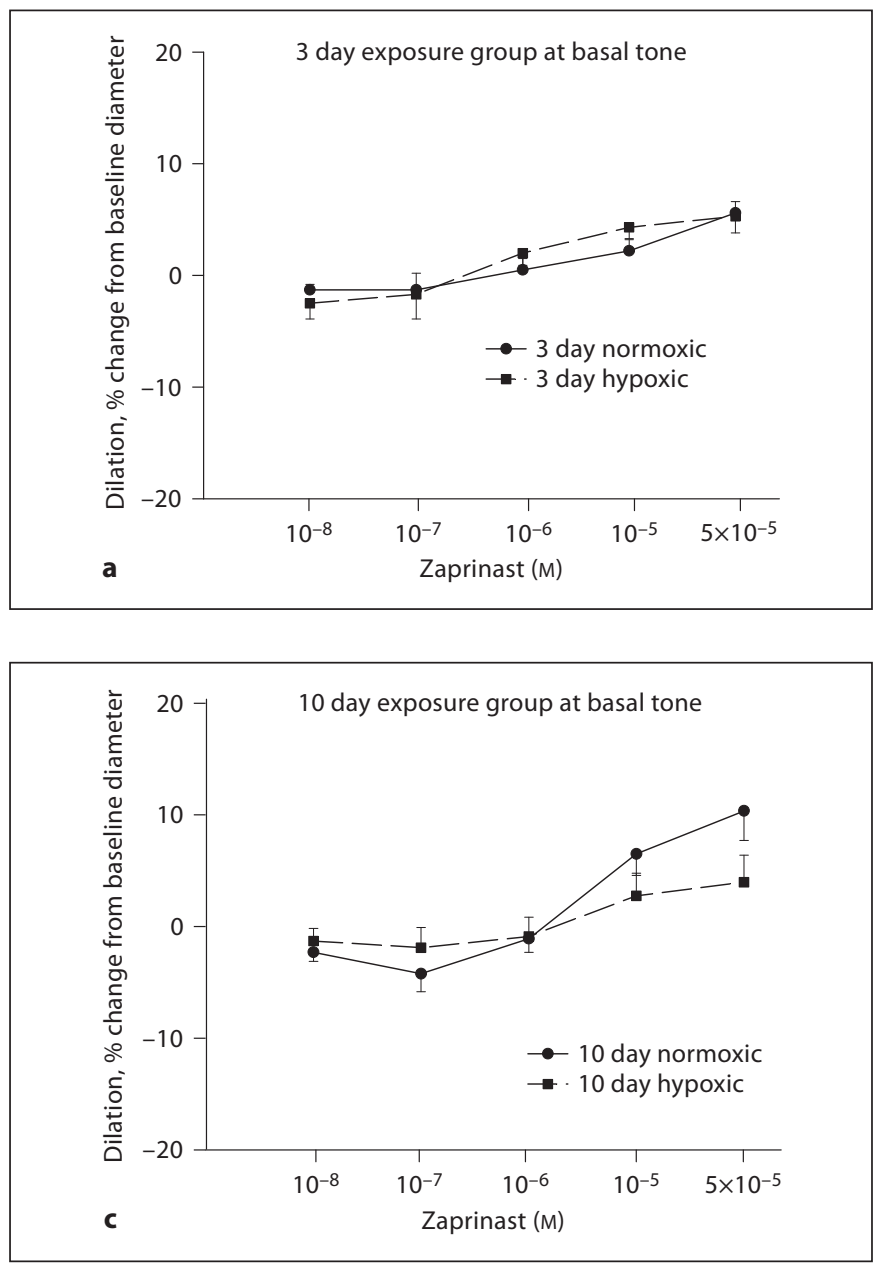

Fig. 1. Changes in diameter in response to zaprinast at basal (a, c) and elevated (b, d) tone in PRAs from 3 and 10 day exposure groups of piglets (a 7 arteries from normoxic and 6 arteries from hypoxic piglets of the 3 day exposure group studied at basal tone; b 9 arteries from normoxic and 12 arteries from hypoxic piglets

\section{Measurement of cGMP PDE Activity in MCA}

These studies were performed to determine whether differences in MCA responses to zaprinast involve altered PDE5 activity. MCA homogenates from all groups of piglets were prepared from frozen tissue and assayed for both total cGMP-hydrolytic PDE activity and zaprinast-inhibited PDE activity using a commercially available colorimetric cyclic nucleotide PDE assay kit following the manufacturer's instructions (Biomol). The difference between cGMP hydrolytic activity in the presence and absence of zaprinast $\left(10^{-6} \mathrm{M}\right)$ was used as an estimate of PDE5 activity.

\section{Drugs and Solutions}

Zaprinast was obtained from Sigma. SNAP was obtained from Biomol. Concentrations for zaprinast and SNAP are the final concentrations in the vessel bath. Composition of the PSS (in $\mathrm{mM}$ ) was: $\mathrm{Na}^{+}, 141 ; \mathrm{K}^{+}, 4.7 ; \mathrm{Cl}^{-}, 125 ; \mathrm{Ca}^{2+}, 2.5 ; \mathrm{Mg}^{2+}, 0.72 ; \mathrm{H}_{2} \mathrm{PO}_{4}^{-}, 1.7$; $\mathrm{HCO}_{3}{ }^{-}, 25$; glucose, 11 .
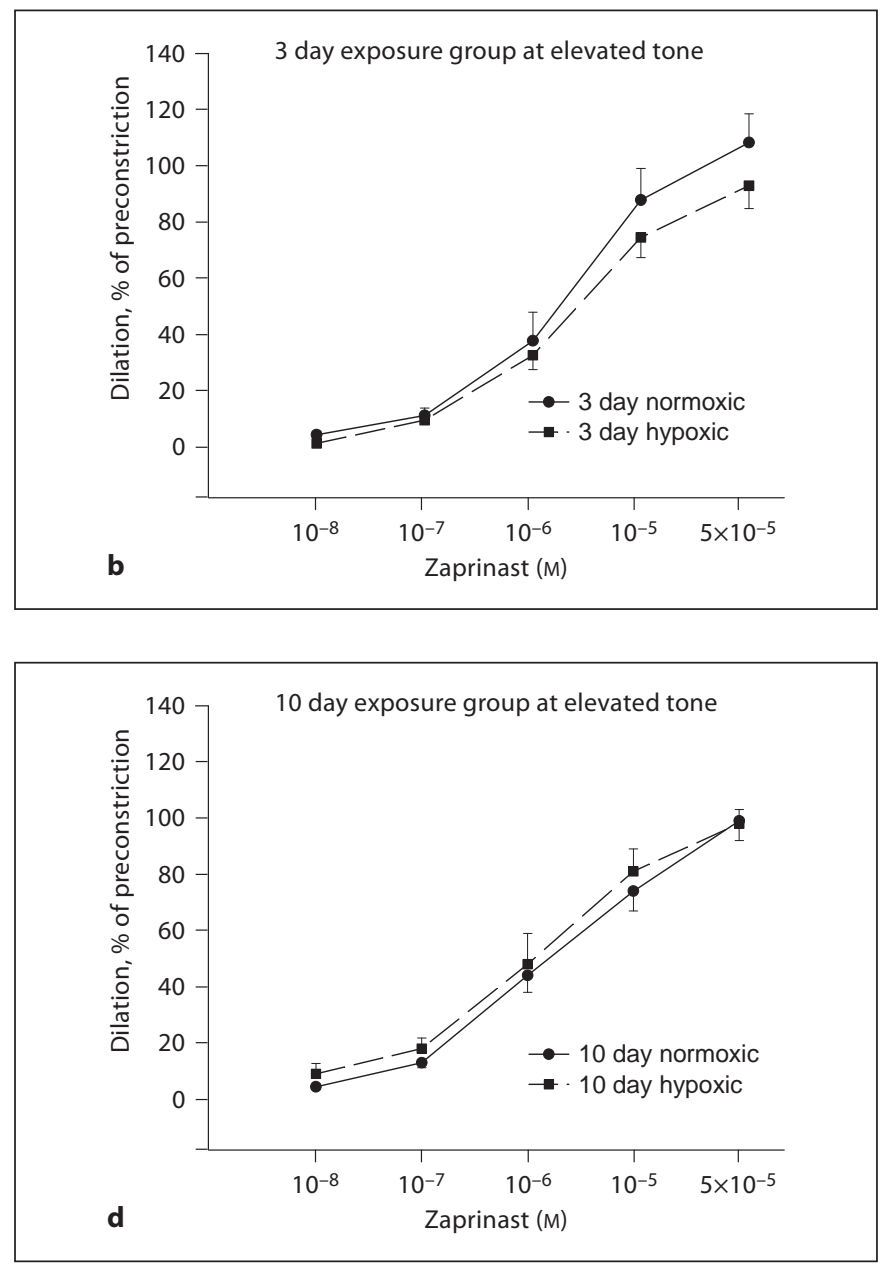

of the 3 day exposure group studied at elevated tone; c 11 arteries from normoxic and 11 arteries from hypoxic piglets of the 10 day exposure group studied at basal tone; $\mathbf{d} 13$ arteries from normoxic and 8 arteries from hypoxic piglets of the 10 day exposure group studied at elevated tone).

\section{Statistics}

Data are presented as means \pm SEM. For cannulated PRA and MCA studies evaluating responses to zaprinast and SNAP, the change in diameter in response to each dose of zaprinast was calculated for all vessels, then compared between normoxic and hypoxic groups using unpaired Student's t test. The diameters of MCA at different pressure steps were compared between normoxic and hypoxic groups or between untreated and zaprinast-treated arteries using unpaired Student's t test. For Western blot analysis, unpaired Student's t test was used to compare densitometry values for PDE5, NOS 1 and NOS 3 between normoxic and hypoxic piglets. Total PDE activity and PDE5 activity were compared between normoxic and hypoxic piglets using unpaired Student's $t$ test. $\mathrm{p}<0.05$ was considered significant. 

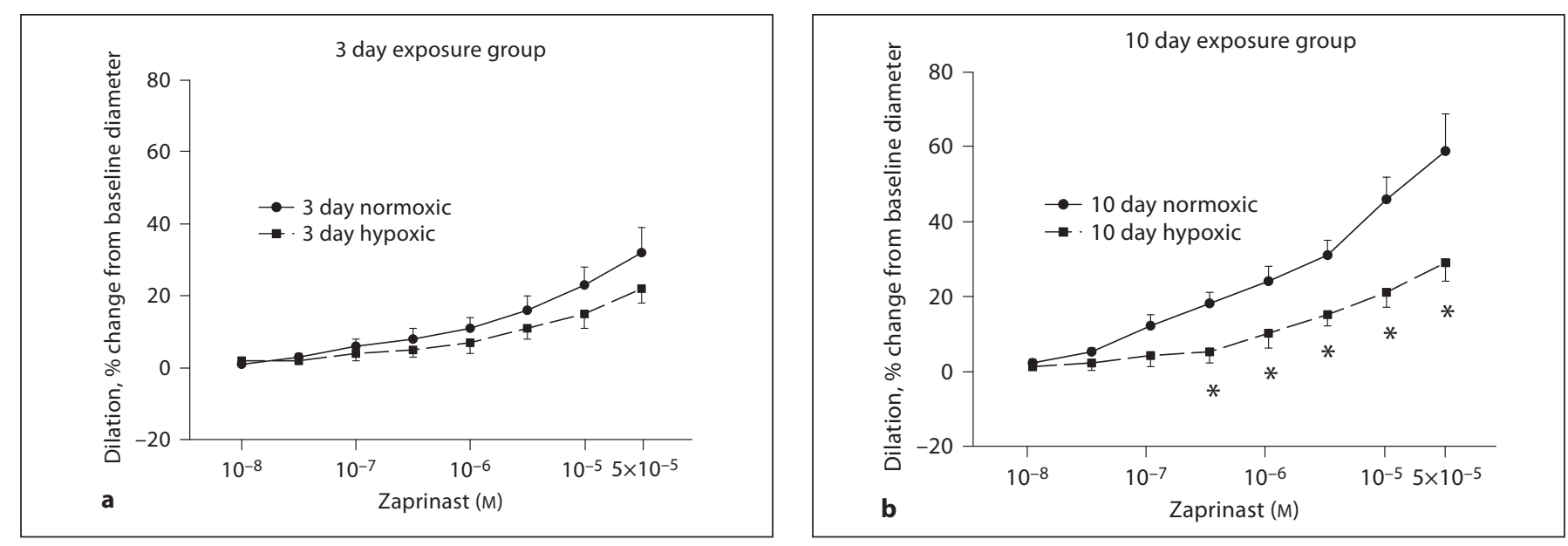

Fig. 2. Responses to zaprinast in MCAs from 3 and 10 day exposure groups of piglets. a Five arteries from normoxic and 6 arteries from hypoxic piglets of the 3 day exposure group. b Seven arteries from normoxic and 6 arteries from hypoxic piglets of the 10 day exposure group. ${ }^{*} \mathrm{p}<0.05$ versus normoxic, unpaired t test.

\section{Results}

Diameters of PRAs used for the cannulated artery studies were similar for all groups: $185 \pm 11,176 \pm 7,194$ \pm 7 and $194 \pm 9 \mu \mathrm{m}$ for PRAs from 3 day normoxic $(\mathrm{n}=16), 3$ day hypoxic $(\mathrm{n}=18), 10$ day normoxic $(\mathrm{n}=24)$ and 10 day hypoxic $(\mathrm{n}=19)$ exposure groups of piglets, respectively.

PRAs from both exposure groups of hypoxic and normoxic piglets dilated similarly to cumulatively added zaprinast regardless of whether they were studied at baseline or at elevated tone (fig. 1a-d).

After the equilibration period, the diameters of MCAs from normoxic and hypoxic piglets were not significantly different in either group: $346 \pm 20,346 \pm 17,335 \pm$ 16 and $348 \pm 20 \mu \mathrm{m}$ for MCAs from 3 day normoxic $(\mathrm{n}=24), 3$ day hypoxic $(\mathrm{n}=30), 10$ day normoxic $(\mathrm{n}=33)$ and 10 day hypoxic $(n=26)$ exposure groups of piglets, respectively.

MCAs from piglets raised in hypoxia for 3 days dilated similarly to cumulatively added zaprinast as their comparable age normoxic piglets (fig. 2a). However, MCAs from piglets raised in hypoxia for 10 days dilated significantly less to zaprinast at concentrations between $5 \times$ $10^{-7}$ and $5 \times 10^{-5} \mathrm{M}(\mathrm{p}<0.05)$ than comparable age piglets raised under normoxic conditions (fig. 2b).

MCA responses to SNAP are shown in figure 3. MCAs from piglets raised in hypoxia for 3 days dilated significantly less to SNAP at concentrations of $5 \times 10^{-6}$ to $10^{-4} \mathrm{M}(\mathrm{p}<0.05)$ than MCAs from piglets raised under normoxic conditions (fig. 3a). However, MCAs from pig- lets raised in hypoxia for 10 days dilated similarly to cumulatively added SNAP as their comparable age normoxic piglets (fig. 3b).

Pressure-diameter relationships for MCAs from all groups of piglets are shown in figure $4 a-f$. Untreated MCAs from the 10 day hypoxic exposure group of piglets dilated less to the highest pressure, $120 \mathrm{~mm} \mathrm{Hg}$, than did untreated MCAs from the comparable age group of normoxic piglets (fig. $4 \mathrm{~b}$ ). Nonetheless, the pressure-diameter relationships were similar between untreated MCAs from both groups of hypoxic piglets and their comparable age normoxic piglets (fig. $4 \mathrm{a}, \mathrm{b}$ ). Of note, the diameter of the MCAs from both the hypoxic and normoxic groups of younger piglets increased markedly when the transmural pressure was raised above $90 \mathrm{~mm} \mathrm{Hg}$ (fig. 4a). Returning the transmural pressure to $60 \mathrm{~mm} \mathrm{Hg}$ did not restore the arteries to their original diameter nor were they able to constrict to $80 \mathrm{mM} \mathrm{KCl}$, thus indicating mechanical damage due to the high pressure. The percent change from baseline diameter with increasing transmural pressure was less in the MCAs from the 10 day exposure group (fig. $4 \mathrm{~b}$ ) than in the 3 day exposure group (fig. 4a) and these arteries did not suffer irreparable mechanical damage due to the increase in pressure. The pressure-diameter curves performed in the zaprinast-treated arteries were similar to those in the untreated arteries regardless of whether they were from animals raised in hypoxia or normoxia for either exposure period (fig. 4c-f).

As shown in figure $5 \mathrm{a}$ and $\mathrm{b}, \mathrm{PDE} 5$ expression was similar in PRAs from hypoxic piglets and their comparable age normoxic piglets. Similarly, PDE5 expression in MCAs 

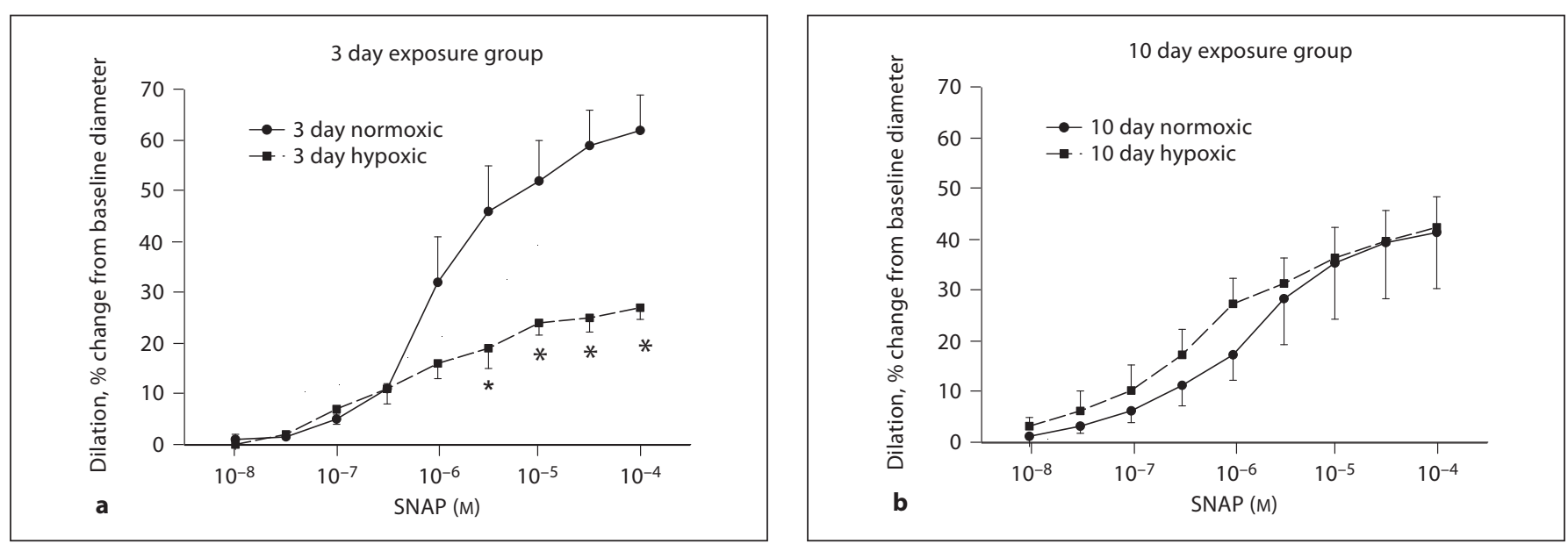

Fig. 3. Responses to SNAP in MCAs from 3 and 10 day exposure groups of piglets. a Four arteries from normoxic and 6 arteries from hypoxic piglets of the 3 day exposure group. b Five arteries from normoxic and 6 arteries from hypoxic piglets of the 10 day exposure group. ${ }^{*} \mathrm{p}<0.05$ versus normoxic, unpaired test.

from piglets raised under hypoxic conditions for 10 days did not differ from their comparable age normoxic piglets (fig. 6c). However, MCAs from piglets raised in hypoxia for 3 days showed less PDE5 expression than comparable age normoxic piglets (fig. 6b). Of interest, there was no difference in PDE5 expression between MCAs from the two age groups of normoxic piglets (fig. 6a). As shown in figures $7 \mathrm{a}$ and $\mathrm{b}$ as well as $8 \mathrm{a}$ and $\mathrm{b}$, NOS 1 and NOS $3 \mathrm{ex}-$ pressions were similar in MCAs from hypoxic piglets and their comparable age normoxic piglets.

Figure 9 summarizes total cGMP-hydrolytic PDE activity and PDE5 activity for MCAs from hypoxic and normoxic piglets. There was no difference in either total PDE activity or PDE5 activity between hypoxic piglets and their comparable age group of normoxic piglets (fig. 9a-d).

\section{Discussion}

The results of this study confirm that a PDE5 inhibitor, in particular zaprinast, can elicit dilation in PRAs from both normoxic piglets and piglets with chronic hypoxiainduced pulmonary hypertension. In addition, and for the first time, we report that zaprinast also elicited dilation in MCAs from these same animals and that the zaprinasttreated arteries exhibited the same pressure-diameter pattern characteristic of arteries from untreated neonatal piglets. Although caution must be taken when extrapolating these findings to human newborns, our findings support the use of PDE5 antagonists as an acute vasodilator for treatment of pulmonary hypertension in conditions asso- ciated with chronic hypoxia. Our assessment of pressurediameter behavior in MCAs does not incorporate changes in blood flow and thus does not completely mimic in vivo conditions of cerebral autoregulation. Nonetheless, our findings of unaltered pressure-diameter behavior indicate that in vivo cerebral artery autoregulation is likely to remain unchanged during the acute use of a PDE5 inhibitor.

Both we and others have previously shown that PDE5 inhibitors function as dilators in pulmonary arteries of newborn animals with pulmonary hypertension [27-33]. Like us, the degree of dilation to PDE5 inhibitors has been shown to be preserved in some newborn animal models of pulmonary hypertension [30]. Since we have previously reported that NO signaling is impaired in the pulmonary circulation of piglets with chronic hypoxiainduced pulmonary hypertension, the preserved dilation to PDE5 inhibitors in PRAs from hypoxic piglets might appear surprising $[22,25]$. However, we previously found that responses to 8-bromo-cyclic GMP are preserved, whereas responses to the NO donor, SNAP, are impaired in PRAs from piglets exposed to 10 days of hypoxia [25]. Thus, findings from this study add to those from our previous studies and continue to show that not all sites of NO signaling are altered in PRAs from hypoxic piglets.

Unlike our hypoxic piglets, some other newborn animal models of pulmonary hypertension exhibit impaired responses to PDE5 inhibitors [29, 32]. Findings regarding PDE5 expression and pulmonary hypertension are also inconsistent. Some animal models of pulmonary hypertension are associated with changes in PDE5 expression [34] while others are not [30]. Moreover, changes in PDE5 

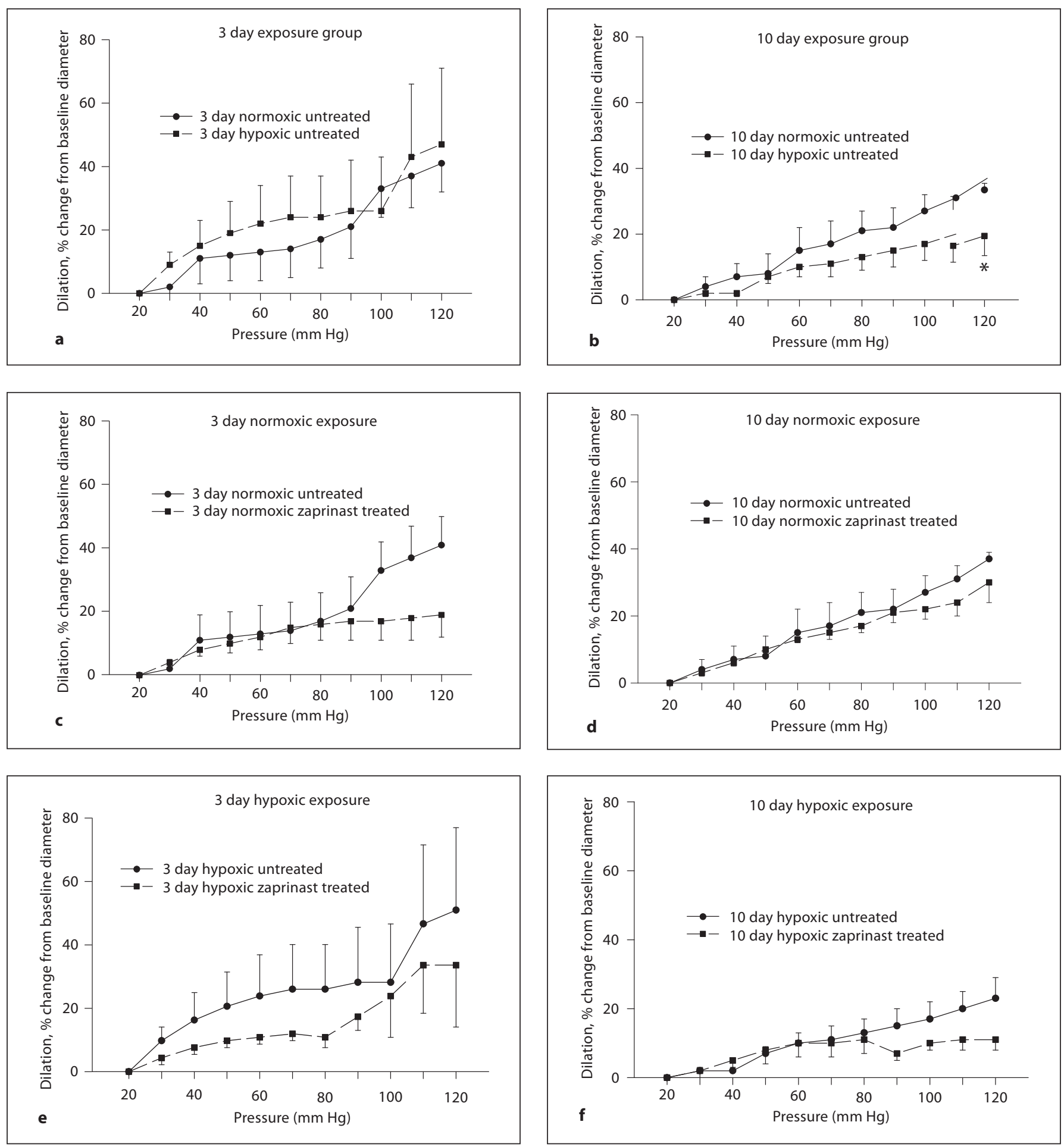

Fig. 4. Responses to changes in transmural pressure in untreated and zaprinast-treated MCAs from 3 and 10 day exposure groups of piglets. a Six arteries from normoxic and 6 arteries from hypoxic piglets of the 3 day exposure group. b Seven arteries from normoxic and 6 arteries from hypoxic piglets of the 10 day exposure group. c Six untreated and 5 zaprinast-treated arteries from normoxic piglets of the 3 day exposure group. $\mathbf{d}$ Seven untreated

and 5 zaprinast-treated arteries from normoxic piglets of the 10 day exposure group. e Six untreated and 5 zaprinast-treated arteries from hypoxic piglets of the 3 day exposure group. $f$ Six untreated and 5 zaprinast-treated arteries from hypoxic piglets of the 10 day exposure group. ${ }^{*} \mathrm{p}<0.05$ versus untreated arteries, unpaired t test. 

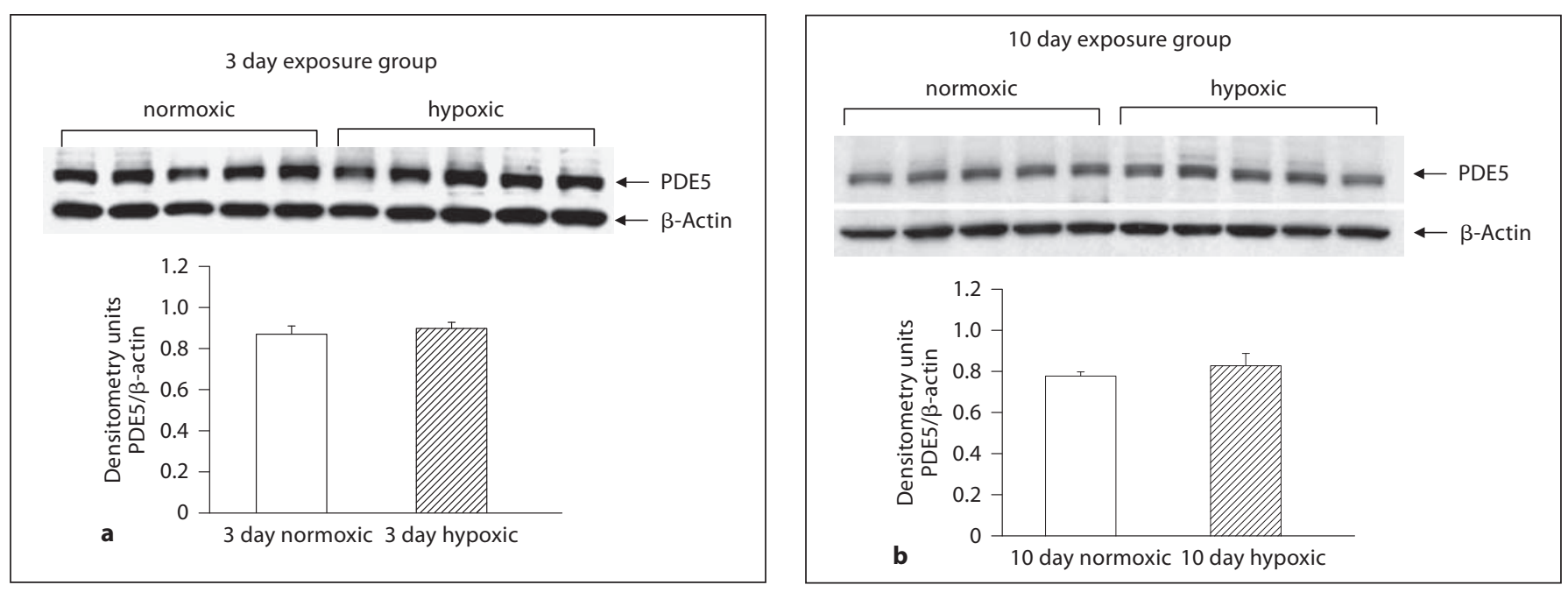

Fig. 5. Immunoblot results and corresponding densitometry for PDE5 in PRA homogenates from 3 (a) and 10 (b) day exposure groups of normoxic $(n=5)$ and hypoxic $(n=5)$ piglets
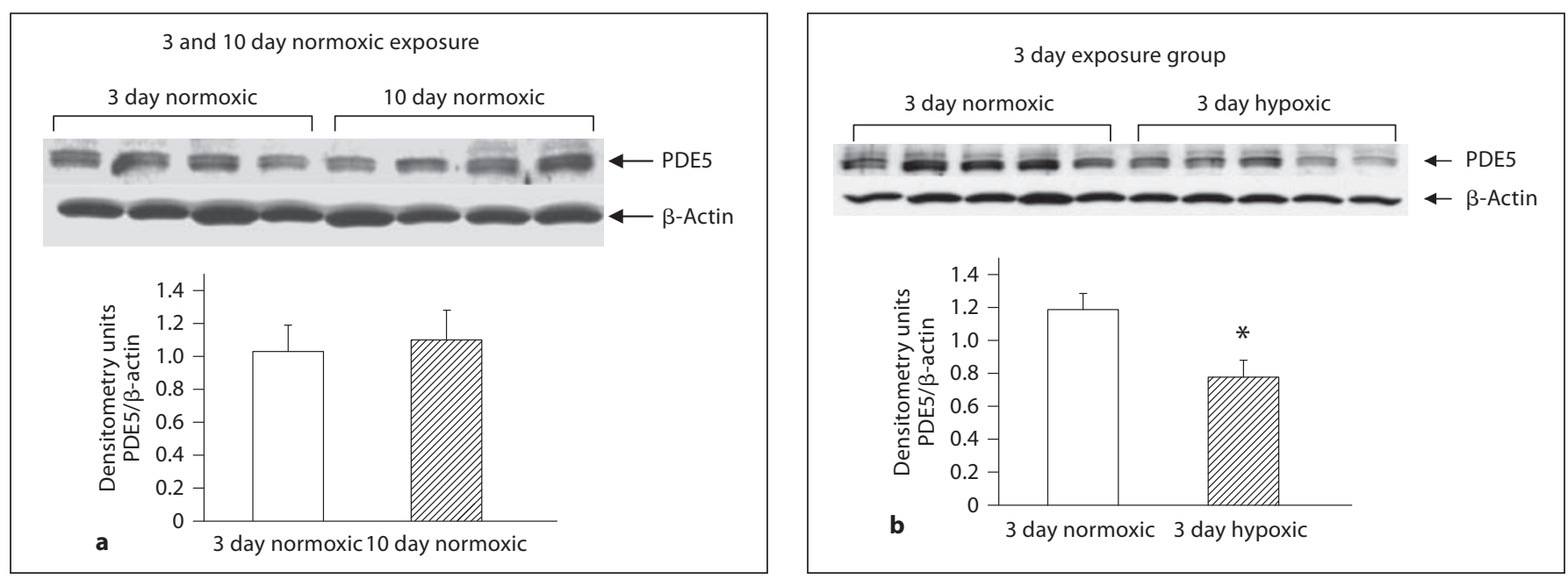

Fig. 6. Immunoblot results and corresponding densitometry for PDE5 in MCA homogenates from 3 day normoxic exposure group $(\mathrm{n}=4)$ and 10 day normoxic exposure group $(\mathrm{n}=4)$ of piglets $(\mathbf{a})$ 3 day exposure groups of normoxic $(n=5)$ and hypoxic $(n=5)$ piglets $(\mathbf{b})$ and 10 day exposure groups of normoxic $(n=5)$ and hypoxic $(\mathrm{n}=5)$ piglets $(\mathbf{c}){ }^{*} \mathrm{p}<0.05$ versus normoxic, unpaired t test.

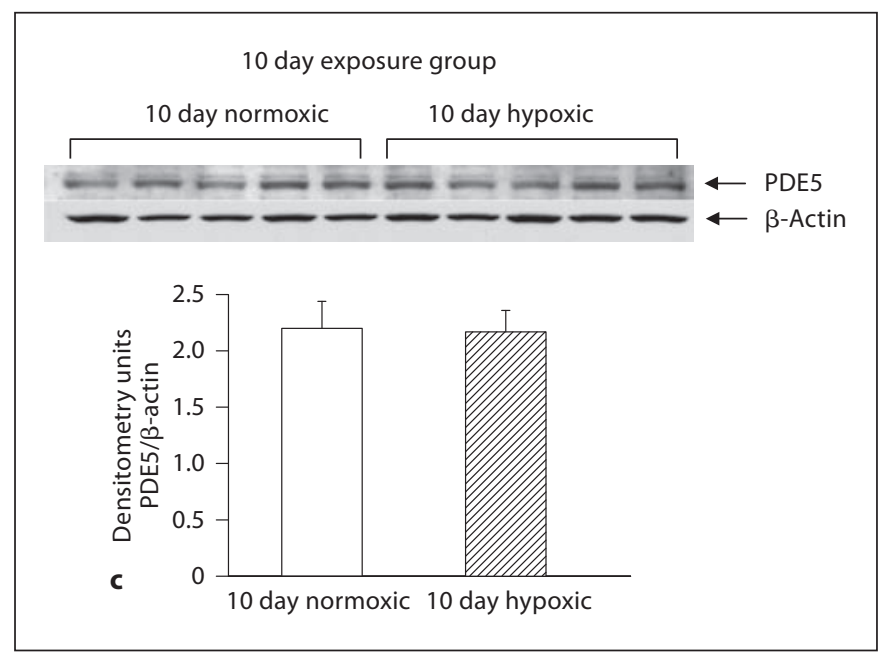

Effect of PDE5 Inhibitor on Pulmonary 

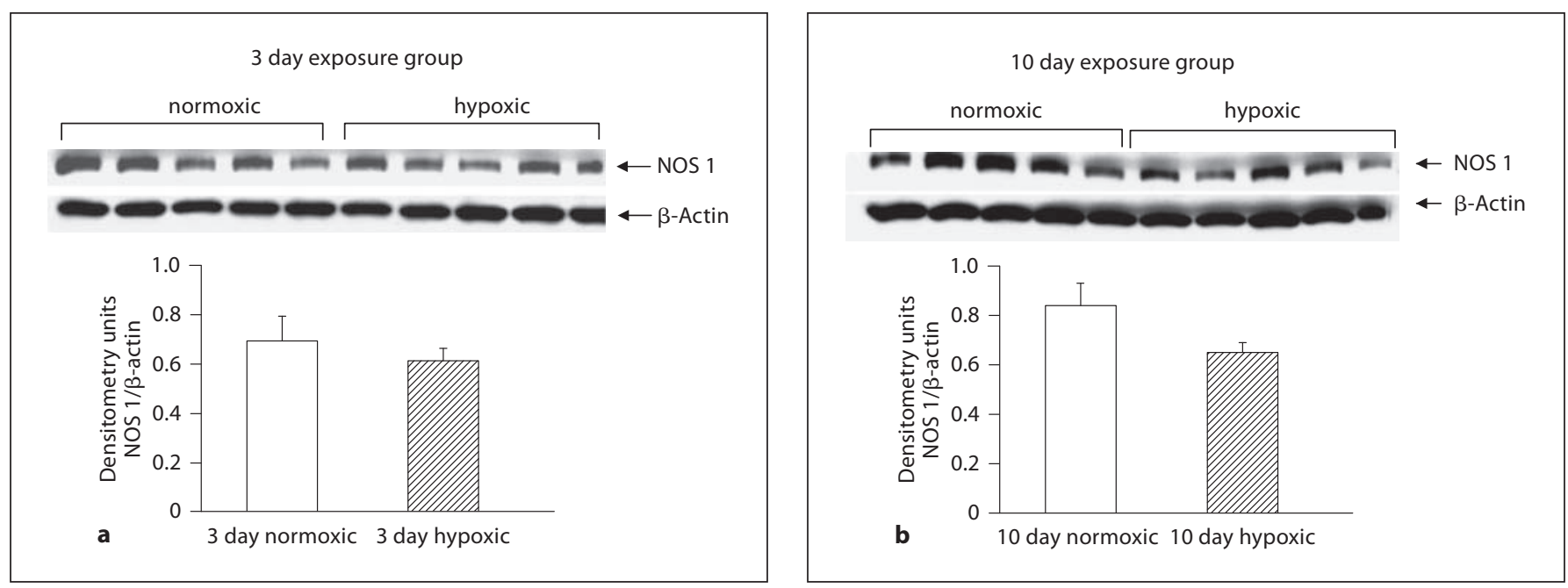

Fig. 7. Immunoblot results and corresponding densitometry for NOS 1 in MCA homogenates from 3 (a) and 10 (b) day exposure groups of normoxic $(n=5)$ and hypoxic $(n=5)$ piglets.
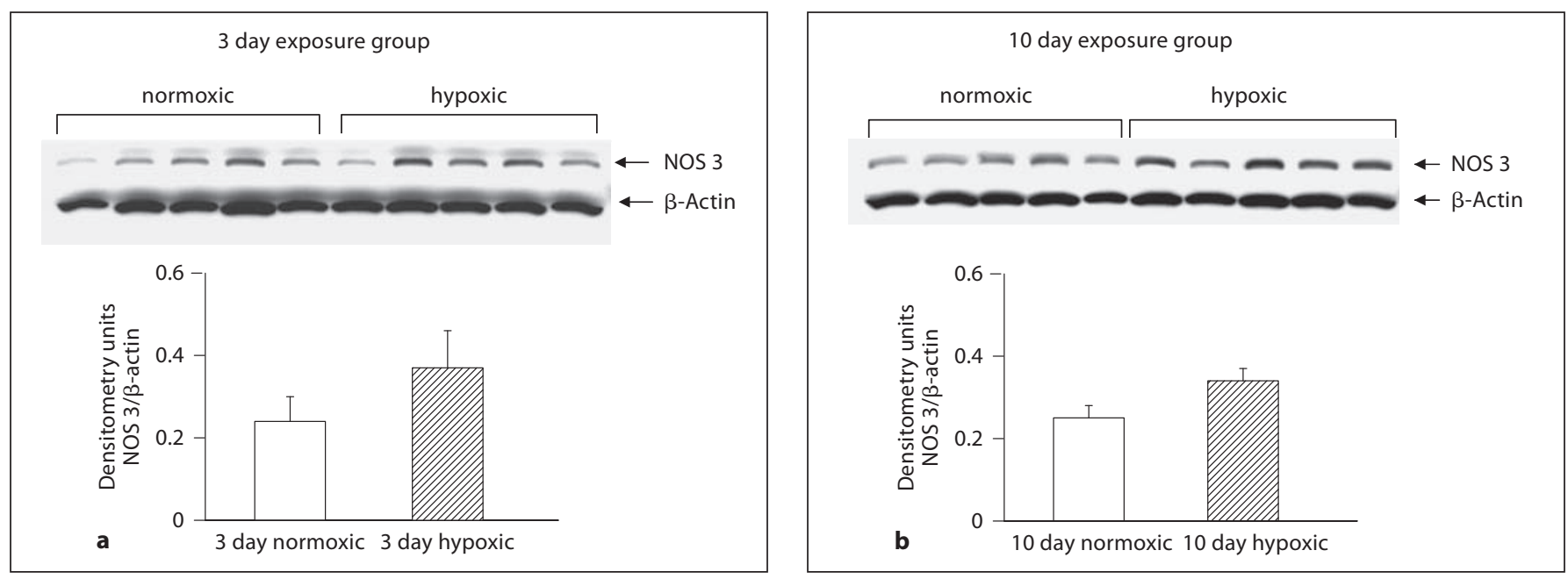

Fig. 8. Immunoblot results and corresponding densitometry for NOS 3 in MCA homogenates from 3 (a) and 10 (b) day exposure groups of normoxic $(n=5)$ and hypoxic $(n=5)$ piglets.

expression do not always correlate with changes in PDE5 activity [30]. Differences between species, type of stimulus and duration of exposure used to induce pulmonary hypertension, age of animals and tissue used for study (lung versus large pulmonary arteries versus small pulmonary arteries) could account for the differences. Thus, it remains uncertain whether or not changes in PDE5 expression and/or activity contribute to the pathogenesis of pulmonary hypertension. Nonetheless, the evidence consistently indicates that PDE5 inhibitors cause acute pul- monary dilation in all currently studied newborn animal models of pulmonary hypertension.

Unlike the pulmonary circulation, there is a scarcity of data available about the influence of PDE5 inhibitors or expression of PDE5 in the newborn cerebral circulation of either normotensive animals or those with pulmonary hypertension. To our knowledge, there are only two other studies. In one report [35] normal piglets were given an acute dose of oral sildenafil and their pial arteries were examined through a cranial window. The arteries of 

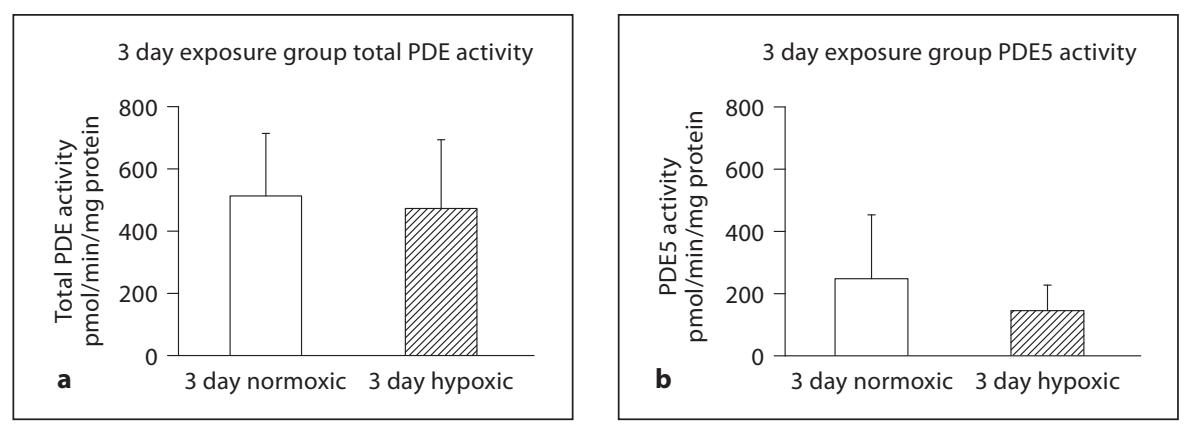

Fig. 9. Total cGMP-hydrolytic PDE activity and PDE5 activity in MCAs from 3 and 10 day exposure groups of normoxic and hypoxic piglets. Total PDE activity (a) and PDE5 activity $(\mathbf{b})$ in normoxic $(n=6)$ and hypoxic $(n=5)$ arteries of the 3 day exposure group and total PDE activity (c) and PDE5 activity $(\mathbf{d})$ in normoxic $(\mathrm{n}=6)$ and hypoxic $(n=6)$ arteries of the 10 day exposure group.
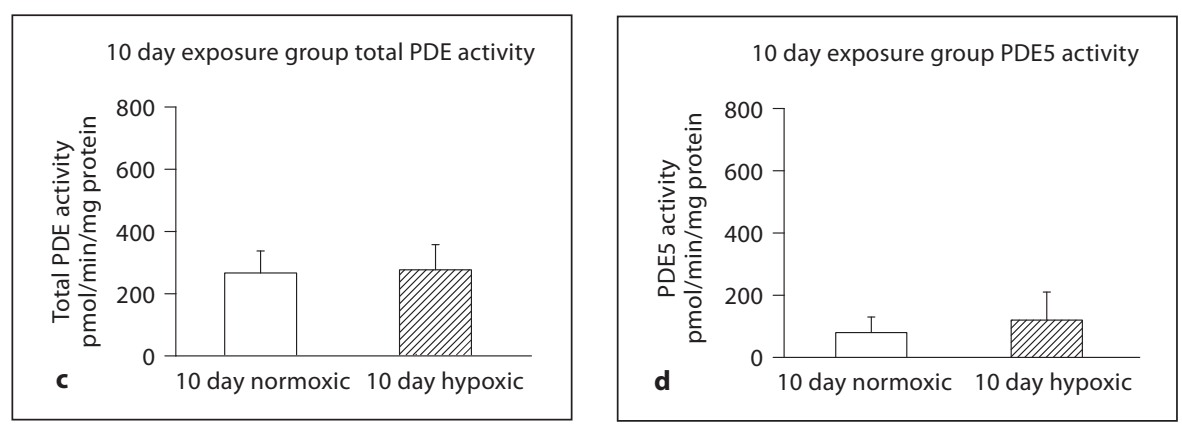

the sildenafil-treated piglets dilated more to nitroprusside than those of untreated piglets and this appeared to be due to an increase in cGMP in the cerebral spinal fluid. This study indicated some interaction of sildenafil with cerebral arteries in newborn piglets in the first few days of life; however, the nature or direction of such effects was not determined. In another study [36] near-infrared spectroscopy was used to evaluate the effect of 3 escalating i.v. doses of sildenafil on cerebral oxygenation in human infants (2.1-20.9 months old) with elevated pulmonary vascular resistance due to congenital heart disease. The findings suggested that sildenafil may increase cerebral blood flow in these infants after cardiac bypass surgery [36]. By comparison to the pediatric population, the effect of PDE5 inhibitors on the cerebral circulation of adult humans and adult animals has received more attention. The results of studies in adult humans and animals are variable, with some showing no evidence that PDE5 inhibitors dilate the cerebral circulation [3739] and others reporting findings consistent with a dilatory influence from PDE5 inhibitors [40], particularly in areas of ischemic injury in rat stroke models [41, 42]. While, on the whole, sildenafil may prove to be an effective therapy for many conditions in adults [36, 43, 44], there remains concern for side effects, many of which involve the cerebrovasculature $[38,45]$, although to date, only a limited number of studies have been done. While there is less known about infants, there was a report of an adverse effect on the retinal vasculature in a neonate treated with sildenafil [46]. However, the possibility for increased risk of retinopathy of prematurity with sildenafil treatment was challenged and has never been confirmed [18]. More credible are reports of systemic hypotension in some infants with congenital heart disease that had been treated with sildenafil [13].

As to PDE5 expression, rat brains were found to express PDE5 at all development ages evaluated, ranging from the fetal period to adulthood, but no information about PDE5 expression in the cerebral vasculature was reported [17]. PDE5 has been detected in adult human cerebral arteries [37] and in guinea pig basilar artery [40].

We add to the literature and report that PDE5 is not only expressed but that PDE5 inhibitors cause dilation in MCAs of both normoxic piglets and those with chronic hypoxia-induced pulmonary hypertension. We also show that PDE5 expression in MCAs from normoxic piglets does not change between 5 and 12 days of postnatal age. In addition, we reveal that the impact of chronic hypoxia on PDE5 expression and responses to PDE5 inhibitors in newborn piglet MCAs appears to differ depending upon the length of exposure to chronic hypoxia. Specifically, we report that the dilator response to PDE5 inhibitors is diminished in MCAs from piglets exposed to the longer but not the shorter duration of exposure to chronic hypoxia. Yet, PDE5 expression in MCAs was altered with the shorter but not the longer duration of hypoxia. 
These findings suggest a discordance between PDE5 expression and the functional response to a PDE5 inhibitor in MCAs from the hypoxic piglets. There are several possible explanations for this discordance. One is that expression of PDEs other than PDE5 are altered during exposure to chronic hypoxia. This merits consideration because although commonly referred to as a PDE5 inhibitor, zaprinast has been shown to inhibit other PDEs including PDE6 and PDE1 [47]. Another possibility is that PDE5 expression does not reflect PDE5 activity [30]. Indeed, the similarity in PDE5 activity in the face of reduced PDE5 expression would explain, at least in part, why zaprinast responses did not differ between MCAs from piglets exposed to 3 days hypoxia and their normoxic controls.

Responses to PDE5 inhibition are affected by basal NO production $[29,48]$. Thus, reduced NO production could contribute to diminished responses to the PDE5 inhibitor in the case of preserved PDE5 expression and activity noted in MCAs from piglets exposed to the longer duration of hypoxia. Supportive of this possibility, responses to the NO donor, SNAP, were similar in MCAs from piglets exposed to 10 days hypoxia and their comparable age normoxic piglets. Of note, our findings also indicate that changed expression of NOS 1 or NOS 3 does not provide an explanation for altered $\mathrm{NO}$ production. However, $\mathrm{NO}$ signaling is complex and known to involve a number of posttranslational modifications of NOS. Further studies will be required to determine all of the impairments in NO signaling that develop in MCAs when piglets are exposed to hypoxia. This would include evaluating alterations in soluble guanylate cyclase expression and/or activity as a possible explanation for the altered responses to SNAP observed in MCAs from hypoxic piglets of the 3 day exposure group.
To our knowledge, we are the first to report that MCA autoregulation is unaltered by a single, acute dose of a PDE5 inhibitor in either normotensive piglets or in piglets with chronic hypoxia-induced pulmonary hypertension. These findings provide some limited evidence regarding safety of use of PDE5 inhibitors in newborns. However, the impact of repeated doses of PDE5 inhibitors on cerebral autoregulation has not been evaluated. Moreover, the potential impact of cerebral dilation on brain blood flow from either acute or prolonged administration of PDE5 inhibitors in newborns with or without pulmonary hypertension is yet to be studied. In addition, the potential effect on other parameters of neurological function, both positive and negative, both related and unrelated to changes in cerebral blood flow must be considered. NO/cyclic GMP signaling is involved in central nervous system regulation of angiogenesis, neurogenesis, axonal outgrowth and synaptic plasticity $[41,43,49]$.

In summary, the present study shows that PDE5 is expressed and provides a target for PDE5 inhibitors to cause dilation in the pulmonary and cerebral circulations of piglets with chronic hypoxia-induced pulmonary hypertension. Most importantly, cerebral autoregulation remains intact with acute PDE5 inhibition. Whether or not cerebral autoregulation remains intact with repeated, chronic doses of PDE5 inhibitors remains an important issue that needs to be addressed in future studies.

\section{Acknowledgements}

We would like to thank John Scott, MD, for his help in performing some of the immunoblot studies with the MCAs. This work was supported by RO1 HL-68572.

\section{References}

-1 Atz AM, Wessel DL: Sildenafil ameliorates effects of inhaled nitric oxide withdrawal. Anesthesiology 1999;91:307-310.

-2 Baquero H, Soliz A, Neira F, Venegas ME, Sola A: Oral sildenafil in infants with persistent pulmonary hypertension of the newborn: a pilot randomized blinded study. Pediatrics 2006;117:1077-1083.

3 Chaudhari M, Vogel M, Wright C, Smith J, Haworth SG: Sildenafil in neonatal pulmonary hypertension due to impaired alveolarization and plexiform pulmonary arteriopathy. Arch Dis Child Fetal Neonatal Ed 2005; 90:F27-F28.

$\checkmark 4$ Hon K, Cheung K, Siu K, Leung T, Yam M, Fok T, Ng P: Oral sildenafil for treatment of severe pulmonary hypertension in an infant. Biol Neonate 2005;88:109-112.

5 Erickson S, Reyes J, Bohn D, Adatia I: Sildenafil (Viagra) in childhood and neonatal pulmonary hypertension. J Am Coll Cardiol 2002;39:402

-6 Juliana AE, Abbad FCB: Severe persistent pulmonary hypertension of the newborn in a setting where limited resources exclude the use of inhaled nitric oxide: successful treatment with sildenafil. Eur J Pediatr 2005;164: 626-629.

7 Keller RL, Hamrick SEG, Kitterman JA, Fineman JR, Hawgood S: Treatment of rebound and chronic pulmonary hypertension with oral sildenafil in an infant with congen- ital diaphragmatic hernia. Pediatric Crit Care Med 2004;5:184-187.

8 Kumar S: Indian doctor in protest after using Viagra to save 'blue babies'. Brit Med J 2002; 325:181.

$\checkmark 9$ Namachivayam P, Theilen U, Butt WW, Cooper SM, Penny DJ, Shekerdemian LS: Sildenafil prevents rebound pulmoanry hypertension after withdrawal of nitric oxide in children. Am J Resp Crit Care Med 2006;174: 1042-1047.

-10 Nassi N, Daniotti M, Agostiniani S, Lombardi E, Favilli S, Donzelli GP: Sildenafil as 'first line therapy' in pulmonary persistent hypertension of the newborn? J Matern Fetal Neonatal Med 2010;23:104-105. 
11 Raja SG, Nayak SH: Sildenafil: emerging cardiovascular indications. Ann Thorac Surg 2004;78:1496-1506.

-12 Schulze-Neick I, Hartenstein P, Li J, Stiller B, Nagdyman N, Hubler M, Butrous G, Petros A, Lange $\mathrm{P}$, Redington AN: Intravenous sildenafil is a potent pulmonary vasodilator in children with congenital heart disease. Circulation 2003;108(suppl II):167-173.

-13 Stocker C, Penny DJ, Brizard CP, Cochrane $\mathrm{AD}$, Soto R, Shekerdemian LS: Intravenous sildenafil and inhaled nitric oxide: a randomized trial in infants after cardiac surgery. Intensive Care Med 2003;29:1996-2003.

-14 Reiss I, Schaible T, van den Hout L, Capoluo I, Allegaert K, van Heijst A, Gorett Silva M, Greenough A, Tibboel D, CDH EURO Consortium: Standardized postnatal management of infants with congenital diaphragmatic hernia in Europe: the $\mathrm{CDH}$ EURO Consortium consensus. Neonatology 2010; 98:354-364.

-15 Travadi JN, Patole SK: Phosphodiesterase inhibitors for persistent pulmonary hypertension in the newborn. Pediatr Pulmonol 2003; 36:529-535.

16 Rabe KF, Tenor H, Dent G: Identification of PDE isozymes in human pulmonary artery ad effect of selective PDE inhibitors. Am J Physiol Lung Cell Mol Physiol 1994;266: 536-543.

-17 Van Staveren WC, Steinbusch HW, Ittersum MMV, Repaske DR, Goy MF, Kotera J, Omori K, Beavo JA, Vente JD: mRNA expression patterns of the cGMP-hydrolyzing phosphodiesterases types 2, 5, and 9 during development of the rat brain. J Comp Neurolo 2003; 467:566-580.

18 Pierce CM, Petros AJ, Fielder AR: No evidence for severe retinopathy of prematurity following sildenafil. Br J Ophthalmol 2005; 89:250.

-19 Schwarz ER, Kapur V, Rodriquez J, Rastogi S, Rosanio S: The effects of chronic phosphodiesterase-5 inhibitor use on different organ systems. Int J Impot Res 2007;19:139-148.

20 Ramaekers VT, Casaer P, Daniels H, Marchal G: Upper limits of brain blood flow autoregulation in stable infants of various conceptual ages. Early Hum Dev 1990;24:249-258.

-21 Fike CD, Kaplowitz MR: Effect of chronic hypoxia on pulmonary vascular pressures in isolated lungs of newborn pigs. J Appl Physiol 1994;77:2853-2862.

-22 Fike CD, Kaplowitz MR: Chronic hypoxia alters nitric oxide-dependent pulmonary vascular responses in lungs of newborn pigs. J Appl Physiol 1996;81:2078-2087.

-23 Fike CD, Pfister SL, Kaplowitz MR, Madden JA: Cyclooxygenase contracting factors and altered pulmonary vascular responses in chronically hypoxic newborn piglets. J Appl Physiol 2002;92:67-74.

-24 Shimoda L, Norens N, Jeutter D, Madden J: Flow-induced resposes in piglet isolated cerebral arteries. Ped Res 1996;39:574-583.
25 Fike CD, Aschner JL, Zhang Y, Kaplowitz MR: Impaired NO signaling in small pulmonary arteries of chronically hypoxic newborn pigs. Am J Physiolo Lung Cell Mol Physiol 2004;286:1244-1254.

26 Turley JE, Nelin LE, Kaplowitz MR, Zhang Y, Fike CD: Exhaled nitric oxide is decreased at an early stage of hypoxia-induced pulmonary hypertension in newborn piglets. Am J Physiolo Lung Cell Mol Physiol 2003;284: 489-500.

27 Binns-Loveman KM, Kaplowitz MR, Fike CD: Sildenafil and an early stage of chronic hypoxia-induced pulmonary hypertension in newborn piglets. Pedatric Pulmonology 2005;40:72-80.

28 Dukarm RC, III FCM, Russell JA, Steinhorn RH: Pulmonary and systemic effects of the phsophodiesterase inhibitor dipyridamole in newborn lambs with persistent pulmonary hypertension. Pediatr Res 1998;44:831837.

29 Dukarm RC, Russell JA, III FCM, Perry BJ, Steinhorn RH: The cGMP-specific phosphodiesterase inhibitor E4021 dilates the pulmonary circulation. Am J Resp Crit Care Med 1999;160:858-865.

30 Hanson KA, Ziegler JW, Rybalkin SD, Miller JW, Abman SH, Clarke WR: Chronic pulmonary hypertension increases fetal lung cGMP activity. Am J Physiolo Lung Cell Mol Physiol 1998;275:L931-L941.

31 Ichinose F, Erana-Garcia J, Hromi J, Raveh Y, Jones R, Krim L, Clark M, Winkler JD, Bloch KD, Zapol WM: Nebulized sildenafil is a selective pulmonary vasodilator in lambs with acute pulmonary hypertension. Crit Care Med 2001;29:1000-1005.

32 Tulloh RM, Hislop AA, Boels PJ, Deutsch J, Haworth SG: Chronic hypoxia inhibits postnatal maturation of procine intrapulmonary artery relaxation. Am J Physiolo Heart Circ Physiol 1997;272:H2436-H2445.

33 Weimann J, Ullrich R, Hromi J, Fujino Y, Clark MW, Bloch KD, Zapol WM: Sildenafil is a pulmonary vasodilator in awake lambs with pulmonary hypertension. Anesthesiology 2000;92:1702-1712.

34 Murray F, MacLean MR, Pyne NJ: Increased expression of the cGMP-inhibited cAMPspecific (PDE3) and cGMP binding CGMPspecific (PDE5) phosphodiesterases in models of pulmonary hypertension. Br J Pharmacol 2002;137:1187-1194.

35 Pourcyrous M, Parfenova H, Leffler CW: The effects of orally administered sildenafil (Viagra) on cerebral circulation in newborn pigs. FASEB J 2006;20:A295.

36 Nagdyman N, Fleck T, Bitterling B, Ewert P, Abdul-Khaliq H, Stiller B, Hubler M, Lange PE, Berger F, Schulze-Neick I: Influence of intravenous sildenafil on cerebral oxygenation measured by near-infrared spectroscopy in infants after cardiac surgery. Pediatr Res 2006;59:462-465
37 Kruuse C, Thomsen LL, Jacobsen TB, Olesen J: The phosphodiesterase 5 inhibitor sildenafil has no effect on cerebral blood flow or blood velocity, but nevertheless induces headache in healthy subjects. J Cereb Blood Flow Metab 2002;22:1124-1131.

38 Kruuse C, Thomsen LL, Birk S, Olesen J: Migraine can be induced by sildenafil without changes in middle cerebral artery diameter. Brain 2003;126:241-247.

-39 Royl G, Balkaya M, Lehmann S, Lehnardt S, Stohlmann K, Lindauer U, Endres M, Dirnagl U, Meisel A: Effects of the PDE5-inhibitor vardenafil in a mouse stroke model. Brain Res 2009;1265:148-157.

$\checkmark 40$ Kruuse C, Rybalkin SD, Khurana TS, Jansen-Olesen I, Olesen J, Edvinsson L: The role of cGMP hydrolyzing phosphodiesterases 1 and 5 in cerebral artery dilatation. Eur J Pharmacol 2001;420:55-65.

41 Li L, Jiang Q, Zhang L, Ding G, Zhang ZG, Li Q, Ewing JR, Lu M, Panda S, Ledbetter KA, Whitton PA, Chopp M: Angiogenesis and improved cerebral blood flow in the ischemic boundary area detected by MRI after administration of sildenafil to rats with embolic stroke. Brain Res 2007;1132:185192.

42 Zhang R, Wang Y, Zhang L, Zhang Z, Tsang W, Lu M, Zhang L, Chopp M: Sildenafil (Viagra) induces neurogenesis and promotes functional recovery after stroke in rats. Stroke 2002;33:2675-2680.

43 Zhang L, Zhang RL, Wang Y, Zhang C, Zhang ZG, Meng H, Chopp M: Functional recovery in aged and young rats after embolic stroke: treatment with a phosphodiesterase type 5 inhibitor. Stroke 2005;36:847-852.

44 Zhang R, Zhang Z, Zhang L, Wang Y, Zhang C, Chopp M: Delayed treatment with sildenafil enhances neurogenesis and improves functional recovery in aged rats after focal cerebral ischemia. J Neurosci Res 2006;83: 1213-1219.

45 Morgan JC, Alhatou M, Oberlies J, Johnston $\mathrm{KC}$ : Transient ischemic attack and stroke associated with sildenafil (viagra) use. Neurology 2001;57:1730-1731.

46 Marsh C, Marden B, Newsome R: Severe retinopathy of prematurity (ROP) in a premature baby treated with sildenafil acetate (Viagra) for pulmonary hypertension. J Br Ophthalmol 2004;88:306-307.

47 Francis SH, Turko IV, Corbin JD: Cyclic nucleotide phosphodiesterases: relating structure and function. Prog Nucleic Acid Res Mol Biol 2001;65:1-52.

-48 Jeffery TK, Wanstall JC: Phosphodiesterase III and $\mathrm{V}$ inhibitors on pulmonary artery from pulmonary hypertensive rats: differences between early and established pulmonary hypertension. J Cardiovasc Pharmacol 1998;32:213-219.

49 Bredt DS, Snyder SH: Nitric oxide: a physiologic messenger molecule. Annu Rev Biochem 1994;63:175-195 